\title{
The Impact of an Insider and Short-selling on Bubble Formation in Experimental Financial Market ${ }^{1}$
}

By

\section{Thorsten Chmura, Ye Bai ${ }^{\#}$, David Bauder}

Thorsten CHMURA: Nottingham Trent University, U.K. E-mail: thorsten.chmura@ntu.ac.uk; Ye BAI: Xi'an Jiaotong-Liverpool University, China, E-mail: ye.bai@,xjtlu.edu.cn (yebai8487@yahoo.com)

David BAUDER: LMU Munich, University of Munich, Germany, E-mail: david.bauder@gmx.de

\section{\# Correspondence to:}

Y. Bai: International Business School Suzhou, Xi'an Jiaotong-Liverpool University, No.111 Ren'ai Road, Dushu Lake Higher Education Town, Suzhou, China, 215123 Tel: +86 (0) 5128816 1728; Email:ye.bai@xjtlu.edu.cn (yebai8487@yahoo.com)

1 We thank the useful comments and suggestions made by participants in the Fifth International Symposium in Computational Economics and Finance (ISCEF), April 12-14, 2018, Paris. 


\title{
The Impact of an Insider and Short-selling on Bubble Formation in Experimental Financial Market
}

\begin{abstract}
This study extends the institutional design of the existing literature focusing solely on short selling by introducing an insider who is informed of the dividend distribution and experienced outsiders who gain information via trading experience. Our findings show that introducing short selling and an insider does reduce the bubble duration and size. At the same time, volatility is significantly reduced. Furthermore, the presence of the single insider reduces the large undervaluation and overall turnover in pure short selling treatment and generates small positive bubbles. Once the outsiders gain information via trading experience, there are small positive bubbles with reduced volatility.
\end{abstract}

JEL: C92; D84; G10

Keywords: Experimental economics; Asset market; Bubble; Short selling; Insider trading; Market efficiency 


\section{Introduction}

Bubbles and financial crises have occurred during the history of financial development (refer to Palan (2013) for detailed survey). Since the framework first introduced by Smith, Suchanek and Williams (1988) (henceforth SSW, 1988), a large number of asset market experiments in the existing literature (for example, Lei, Noussair, and Plott, 2001; Dufwenberg, et al., 2005; Haruvy and Noussair, 2006; Haruvy, et al., 2007) consistently show bubbles in many different environments. However, despite some recent efforts, there is still room for further research regarding to the design of an institution that eliminates deviations from fundamental values $(\mathrm{FV})^{2}$ in experimental asset market (Ackert, et al., 2006). Our study tests the simultaneous influence of an insider and the possibility of short selling on speculative bubbles in experimental asset markets.

There is mixed empirical evidence on whether insider transactions produce more informative security prices and enhance market efficiency. Corporate insiders, e.g., executives, are able obtain significant abnormal returns by using their superior information about their firm value (Gider and Westheide, 2016). Literature suggest that restriction on insider trading reduces information asymmetry and enhances liquidity, which allows more informed risk arbitrage hence improves the information efficiency of prices (Bushman et al., 2005; Aussenegg, et al., 2017). Similarly, some experimental studies create a "soft" form of insider by providing some participants with the knowledge of the paid

\footnotetext{
2 Abbreviation list: fundamental values (FV); Smith, Suchanek and Williams (1988) (SSW, 1988); the QL6-treatment in Haruvy and Noussair (2006) (HN-QL6); Shanghai Jiao Tong University (SJTU); no-short-selling, (SSW); (short selling and insider, (SSI)); experimental currency units (ECU)
} 
dividend in the current and/or following period, they show that markets with asymmetrically informed traders have smaller and short-lived bubbles than markets with symmetrically informed or uninformed traders (Oechssler, et al., 2011; Sutter, et al., 2012).

Another strand of literature (for example, Haruvy and Noussair, 2006; Füllbrunn and Neugebauer, 2012; Fellner and Theissen, 2014; Chiang et al., 2017) show that short-selling constraints can reduce asset prices and liquidity but increase their volatilities. Saffi and Sigurdsson (2011) argue that this happens because short-selling constraints have a significant impact on informed investors, which reduces the informative value of prices. This in turn increases the amount of risk burden on uninformed investors, who would ask for lower prices to compensate for this extra risk. It is well documented that short sellers are sophisticated traders and possess superior information, for example, they can identify overvalued stocks (e.g. Karpoff and Lou, 2010; Hirshleifer, Teoh, and Yu, 2011) or are particularly good at analysing information (Engelberg, et al., 2012). Furthermore, short sellers trade a considerable amount (Diether, et al., 2009). Together these features make short sellers an important group of "informed" market participants whose transactions may directly and significantly affect both uninformed outsiders and informed insiders. Particularly, in the presence of short sellers, insiders would fear that short sellers have access to the same information and hence compete with them to trade with this information advantage. Consequently, the fear of such trading competition will speed up the rate at which private information is released to the market (Foster and Viswanathan, 1993), drive down the price at which insiders can sell their shares hence endanger the profitability of 
insider sales. A study that is close to ours is Massa et al. (2015). This empirical study shows a specific channel through which short sellers accelerate information releasing by inducing insiders to sell more (shares from their existing stakes) at higher speed in order to pre-empt the potential competition from short sellers. Going further by differentiating various types of insiders, To et al. (2017) find that the executive directors use the more timely private information to beat the short sellers in trading hence the profitability of insider trades are only reduced for non-executive directors after short selling is permitted. These empirical results are important as they show that the interaction with other types of "informed" investors may accelerate the release of new information by insiders and significantly affect the way information propagates in the financial markets.

However, empirically identifying and measuring bubbles are never easy tasks since FVs are difficult to determine in real markets. It is equally impossible to collect the different opinions on the market. With these challenges, experiments may be useful tools as controlled laboratory experiment asset markets can control both for an asset's FV by letting the experimenter define it exogenously and by instructing market participants directly about the process generating the FV (Dufwenberg, et al., 2005). The seminal study, Haruvy and Noussair (2006) has relaxed the short-selling constraints in the classical SSW (1988) design. Their results suggest a potential shortcoming of short selling, i.e. it may overcompensate for bubbles and lead to undervaluation relative to FV. Based on the results of the QL6-treatment in Haruvy and Noussair (2006) (henceforth HN-QL6), they argue that instead of inducing rational expectations, short selling simply affects the supply of and demand for the asset, 
which is partially determined by forces rather than the relationship between current prices and FV. Haruvy and Noussair (2006) further explore the origins of this demand and supply for the asset by simulating different types of traders especially speculators. Their results suggest a lack of common knowledge of rationality on the part of market participants. Therefore, Haruvy and Noussair (2006) suggest that the institution design should facilitate the subjects' understanding of the connection between the expected future dividend stream and the current value a rational trader places on the asset. To test this specific institutional design with laboratory experiments, built upon SSW (1988), ${ }^{3}$ our study extends the institutional design in HN-QL6 to test an explicit economic channel through which short selling can (indirectly) improve the price efficiency of the economy via their influence on insiders. Compared to Haruvy and Noussair (2006) (especially QL6 treatment), we facilitate subjects' comprehension of the connection between the expected future dividend stream and the current value a rational trader places on the asset in two ways: we alter their institution design by first introducing an insider who is informed of the dividend distribution then introducing the experienced outsiders who gain information via building up experience in trading.

Furthermore, we can argue that if traders' beliefs are distributed with a mean at the $\mathrm{FV}^{4}$ of the asset,

\footnotetext{
3 Although relative to SSW (1988), we have changed two variables at the same time, the existence of a substantial body of previous experimental work (Detailed discussions refer to the introduction and results sections.) with similar markets permit us to compare and interpret our results within a sizable literature and to verify that our procedures generate similar outcomes when applied in the same environment.

${ }^{4}$ In this study, we refer to the FV as the expected dividends of the sum of the shares and the intrinsic value as the truly realised dividends.
} 
the price should closely track that FV (Haruvy and Noussair, 2006). When only one subject is provided with the intrinsic value, we expect that this subject as an insider is able to exploit this information advantage so that she gains the highest profit. While based on the experiment results in Plott and Sunder (1982), it is impossible to distinguish the profits of the insider from those of the outsiders. Potentially, there could be a large gap between the insider's profit level and that of the second highest profiteer. The insider should exploit her knowledge by buying undervalued assets (when the offered asset price is lower than the intrinsic value) or by selling overvalued assets (when the offered asset price is higher than the intrinsic value). Therefore, the insider is expected to focus on the intrinsic value instead of the average price. Furthermore, it is also expected that given her information advantage, the insider should be the most active participant. Hence, we also contribute to the literature on insider by taking a closer look on the insiders' investment behaviour and their profitability relative to the outsiders when both types of subjects can sell short.

Following SSW (1988), experiment studies show that bubbles tend to occur with inexperienced traders but not with experienced traders who have participated many times in the same type of market. In line with King et al. (1993) results, Dufwenberg, et al. (2005) suggest that even by having a small fraction (one-third) of experienced traders, bubbles are eliminated, or at least substantially reduced. Furthermore, prices in markets where traders have mixed experience are similar to markets with only twice-experienced traders. Similarly, experimental evidence suggests when uninformed traders accumulate experience, asymmetric information contributes to the reduction of bubbles 
(Haruvy, et al., 2007; Sutter, et al., 2012). We also contribute to the experiment literature by examining whether institution design on insider trading restrictions can be offset to some extent by those experienced subjects in terms of bubble formation. Traders can form expectations about the future prices based on their experience. Experiments in the existing studies normally create "experienced" subjects by repeating trading in several rounds in the same environment. While in our study, subjects can also form expectation or gain information advantage based on their experience of being an insider. Therefore, we differentiate experienced subjects according to whether she is 'an informed subject based on her insider experience' or 'an uninformed outsider becoming informed by accumulating trading experience'. Therefore, unlike Dufwenberg et al. (2005), we can also test whether information asymmetry concentrates on a single experienced subject in each session is sufficient to reduce bubbles.

Based on the above discussions and review of the literature, we formulate six conjectures:

$\mathrm{H}_{1}$ : Bubbles are smaller when an insider is present and the subjects have the opportunity to sell short. The price deviation is positive instead of negative when an insider is allowed in HN-QL6.

$\mathrm{H}_{2}$ : Outsiders trade more cautiously when there is an insider hence the turnover decreases when an insider is allowed in HN-QL6.

$\mathrm{H}_{3}$ : Volatility is reduced in these sessions, where there are the presence of an insider and possibility of short-selling.

$\mathrm{H}_{4}$ : The additional information given to the insider does not increase her profit, due to the fact that 
prices are driven by all participants and the nature of the game.

$\mathrm{H}_{5}$ : Profits are more unequally distributed when short selling is allowed and an insider participates in a session.

$\mathrm{H}_{6}$ : Experienced subjects reduce the bubble formation and inequality in profit distribution.

The remainder of the study is organized as follows: section 2 discusses the experimental designs and measurements, in section 3 we summarize the results. Section 4 concludes.

\section{Experimental Design and Measurements}

\subsection{Experimental market participants}

The data were gathered in 12 experimental sessions conducted at the Vernon Smith Experimental Economics Research Center in Shanghai Jiao Tong University (SJTU) located in Shanghai, China. We are able to replicate the results by SSW (1988) in China. This allows us to examine explicitly whether cultural or environmental differences have impact on subjects' behaviour. Our Chinese assistants in SJTU invited subjects through an online forum via the university intranet. All subjects participated were undergraduate or graduate economics students at SJTU with no experience and knowledge of asset market experiments. Nine subjects participated in each session. Each session lasted for 15 periods therefore the total number of subjects participating in this experiment was 108 . Each participant was paid a show-up fee of RMB5 (about US\$ 0.79) plus their earnings in the experiment. Negative earnings are possible but are capped to zero in the payoffs. Participants then 
receive initial cash and asset endowments.

\subsection{Timing}

Each period lasted four minutes. On average, each session lasted approximately 1 hour and 20 minutes. All experiments have been conducted by using Ztree (Fischbacher, 2007). Upon arrival, subjects were trained to use the computerized asset market for six minutes. During this practice period, the experimenter reads aloud the instructions, consisting of a step-by-step explanation of how to make bids and offers. The instructions ${ }^{5}$ have been translated into Chinese using the back translation procedure described in Brislin (1970). During the rest of the practice period (around 5 minutes), subjects practiced buying and selling by using the interface. All questions were answered and the subjects were informed that their activities during this practice period would not be counted towards their final earnings. After the training was completed, the remainder of the instructions, which described all the other aspects of the experiment, were read aloud. The 15 periods of the session then proceeded. Subjects were free to trade at any time, provided that they did not violate either the short selling or cash balance constraint in the session.

\subsection{Treatments}

The experiment consisted of 225 periods in total. In the first six sessions (Sessions 1 - 6, SSW sessions), we replicated the classical (SSW, 1988) design in which neither short selling nor an insider

\footnotetext{
5 The detailed instructions are included in Appendix B.
} 
was allowed. By replicating the SSW (1988) experiment in China and finding consistent results to the original paper, we provide robustness checks when the experiments are conducted in different environment. Hence, we are assured that our subject pool is internal valid and replicable for conducting the following two treatments. In the second six sessions (Sessions 7 - 12, SSI sessions), Similar to HN-QL6, we allowed for short selling up to six positions. Furthermore, an insider, who was provided with information of the paid dividend distribution presented in these sessions. The presence of an insider was common knowledge to all the subjects. In the last three sessions, (Sessions 10 - 12, EXP sessions), we allowed the subjects to play two rounds ( $2 \times 15$ periods) of games, hence creating "experienced" subjects in the second round. We included the first round in these sessions in SSI whereas we identified the second round as an independent session, EXP-sessions. Subjects were not informed about the second 15-period in the experiment prior each session. We announced that we would conduct the second 15-period after the first 15-period ended. We also informed that subjects would receive the total payoff for both 15-period at the end of all 30-period.

\subsection{Dividend information}

The dividend was drawn independently and randomly for each session in each period out of $\{0,8,28$, $60\}$ experimental currency units (ECU) and was paid at the end of each period. ${ }^{6}$ The expected

\footnotetext{
${ }^{6}$ Unlike Sutter, et al. (2012) who fix the dividend payments, we argue that it is possible that the insider is strongly influenced by the intrinsic value which she knows by definition. It is part of our research question to explore how an insider reacts to different intrinsic values, especially to draw conclusions on how her information advantage affects the profit distribution.
} 
dividend payment per period was 24 ECU. The fundamental value of the asset in any period $t$ equalled to 24(16-p), where $p$ was the number of the current period. At the beginning participants were endowed with assets and cash in three ways: Type I started with three assets and 255 ECU; Type II started with two assets and 585 ECU and Type III was endowed with one asset and 945 ECU. The insider is randomly assigned among these three types. Each subject's cash and assets were carried over from one period to the next, except EXP sessions where the participants' endowment after the first 15-period was stored and saved. At the beginning of the second 15-period the game was restarted with the initial configuration. The average payoff over all sessions was RMB36. ${ }^{7}$

\subsection{Bubble measurements}

This section explains the bubble measures adopted in this study. The existing literature has neither consensus on what constitutes a bubble nor the appropriate bubble measures accepted in general.

Stöckl, et al. (2010) propose three evaluation criteria ${ }^{8}$ and two measures (Relative Absolute Deviation and Relative Deviation) which fulfill these criteria. However, individual researchers may have different views on these criteria and measures and also each measure has different advantages. Therefore, in this study, we adopt several measures based on the literature as a mean of robustness

\footnotetext{
7 The detailed information on average holding value and intrinsic holding value are included in Tables B1, B2, C1 and C2 in the Appendix.

${ }^{8}$ Relation between $F V$ and price, (b) monotonicity in the difference of $F V$ and prices and (c) independence from the absolute level of the $F V$ and the number of periods.
} 
check. Table 1 presents the definitions and explanations of all the measures adopted in this study.

Haruvy and Noussair (2006) apply several bubble measures such as Total Dispersion (TD) and

Average Bias $(\mathrm{AB})$ and in Table 1 we use bold font for these bubble measures applied in Haruvy and

Noussair (2006), based on which we can make relevant comparisons.

Table 1 A list of measures and explanations

\begin{tabular}{|c|c|c|c|}
\hline Measure & Definition & Explanation & Note \\
\hline $\begin{array}{l}\text { Relative } \\
\text { Absolute } \\
\text { Deviation } \\
\text { (RAD) }\end{array}$ & $R A D:=\frac{\frac{1}{N} \sum_{p}\left|\bar{P}_{p}-F V_{p}\right|}{|\overline{F V}|}$ & $\begin{array}{l}\text { An appropriate measure for mispricing } \\
\text { which is independent from the number of } \\
\text { periods and on the absolute level of } F V \text {. }\end{array}$ & $\begin{array}{l}R A D \text { equals to } 0.2 \text { indicating that } \\
\text { on average mean price per period } \\
\text { differs } 20 \% \text { from the average } F V .\end{array}$ \\
\hline $\begin{array}{l}\text { Relative } \\
\text { Deviation (RD) }\end{array}$ & $R D:=\frac{\frac{1}{N} \sum_{p}\left(\bar{P}_{p}-F V_{p}\right)}{|\overline{F V}|}$ & $\begin{array}{l}\text { A positive } R \frac{\sim}{|F V|} \text { idicates overvaluation } \\
\text { compared to } \\
\text { negative value. }\end{array}$ & \\
\hline Amplitude (A) & $A:=\max _{p}\left(\frac{\overline{p_{p}}-F V_{p}}{F V_{p}}\right)-\min _{p}\left(\frac{\overline{P_{p}}-F V_{p}}{F V_{p}}\right)$ & $\begin{array}{l}\text { It measures the difference between the } \\
\text { largest and the smallest deviations from } \\
\text { FV. It refers to the magnitude of overall } \\
\text { price changes and can be used as a } \\
\text { (naive) measure for volatility. }\end{array}$ & $\begin{array}{l}\text { Haruvy and Noussair (2006) } \\
\text { normalize the difference by } F V \text { in } \\
\text { the same period while Noussair et } \\
\text { al. (2001) use } F V \text { of the first period. }\end{array}$ \\
\hline $\begin{array}{l}\text { Total } \\
\text { Dispersion } \\
\text { (TD) }\end{array}$ & $T D:=\sum_{p} \mid$ Median $P_{p}-F V_{p} \mid$ & $\begin{array}{l}\text { TD is defined as the sum of the absolute } \\
\text { deviation of the median price in period } p \text {. } \\
P_{p} \text { from FV. is }\end{array}$ & $\begin{array}{l}\text { As a measure of mispricing, by } \\
\text { using the median, TD can avoid } \\
\text { overweighting the potential } \\
\text { outliners.. The higher the TD is, the } \\
\text { larger are the deviations from FV. }\end{array}$ \\
\hline $\begin{array}{l}\text { Average Bias } \\
\text { (AB) }\end{array}$ & $A B:=\frac{\sum_{p} \mid \text { Median } P_{p}-F V_{p} \mid}{N}$ & $\begin{array}{l}\text { Similar to } T D, \mathrm{AB} \text { is the average } \\
\text { deviation of the median price from } \mathrm{FV} \text { in } \\
\text { the same period. }\end{array}$ & $\begin{array}{l}\text { A negative } A B \text { indicates on average } \\
\text { negative deviations from } F V \text {, } \\
\text { conversely for a positive } A B \text {. Thus, } \\
\text { AB can indicate undervaluation or } \\
\text { overvaluation. }\end{array}$ \\
\hline Turnover (T0) & $T O:=\frac{\sum_{p} q_{p}}{T S U}$ & $\begin{array}{l}q_{p}: \text { the number of traded units in period } \\
p ; T S U: \text { the total stock units the } \\
\text { participants hold ( } 18 \text { in each session) }\end{array}$ & $\begin{array}{l}\text { TO is a measure for liquidity. The } \\
\text { larger the value, the higher the } \\
\text { liquidity. }\end{array}$ \\
\hline $\begin{array}{l}\text { Normalized } \\
\text { Deviation } \\
\text { (ND) }\end{array}$ & $N D:=\frac{\sum_{p} \sum_{i}\left|P_{i p}-f_{p}\right|}{E x R \cdot T S U}$ & $\begin{array}{l}P_{i p:} \text { the price of transaction } i \text { in period } p, \\
\text { ExR: the exchange rate between ECUs } \\
\text { and RMB }(E x R=40 \text { in this } \\
\text { experiment }), f_{p:} \text { FV in period } p\end{array}$ & $\begin{array}{l}\text { A high } N D \text { requires (i) high trading } \\
\text { volumes and (ii) price deviations } \\
\text { from } F V \text { - sufficient to interpret a } \\
\text { bubble. }\end{array}$ \\
\hline $\begin{array}{l}\text { Boom- and } \\
\text { Bust-Duration }\end{array}$ & $\begin{array}{l}\text { Boom: the number of } \\
\text { consecutive periods in which } \\
\text { the median price of the } \\
\text { period is higher, and } \\
\text { conversely for a bus }\end{array}$ & $\begin{array}{l}\text { This measure indicates the duration of a } \\
\text { bubble. }\end{array}$ & $\begin{array}{l}\text { It is a useful complement to other } \\
\text { bubble measures. . }\end{array}$ \\
\hline Volatility & $\operatorname{vol}_{j, p}:=\frac{\sum_{\theta=1}^{\Theta}\left|\ln P_{j, p, \theta}-\ln P_{j, p, \theta-1}\right|}{\Theta}$ & $\begin{array}{l}\text { Following Hanke, et al. (2010), we proxy } \\
\text { market volatility by the average of } \\
\text { absolute returns in each trading period. } \theta \text { : } \\
\text { each transaction; } \Theta \text { : all transactions in } \\
\text { period } p \text { and market } j\end{array}$ & \\
\hline
\end{tabular}

Note: $1 . \overline{P_{p}}$ is the average price in period $p, N$ the total number of periods and $\overline{F V}$ the average $F V$. 2. Table 1 we use bold font for these bubble measures applied in Haruvy and Noussair (2006), based on which we can make relevant comparisons.

\section{Results}

3.1 An overview of bubble formation and volatility in three treatments 
This section presents an overview and a comparison of our results for each treatment in view of bubble formation and volatility. Figure 1 plots the average mean price of the treatment (in thick grey line), the FV (the thick black line) and the mean price of individual sessions (thin grey lines). The positive deviations in the SSW session can be observed in almost all the individual sessions throughout the 15 periods. This is in line with SSW (1988) and the following literature when short selling and insiders are not allowed in the experiment. Table 2 presents the average bubble measures cross all the sessions in three treatments. ${ }^{9}$ Given the nature of experimental research, our sample sizes are relatively small. To conduct non-parametric tests, we adopt the two-sided Wilcoxon signed rank test to test the statistical significance of our results. In line with Figure1, the mean price (P) results show that SSW sessions on average have the largest deviations (228.44) from the mean FV (192). The second largest deviation is in SSI sessions (198.04). On the other hand, EXP sessions have negative deviations (170.08). In general, most of the bubble measures in Table 2 provide fairly consistent results on the differences between SSI and SSW sessions, though some results are not statistically significant.

\footnotetext{
9 The detailed information on each session trading is included in the appendices.
} 

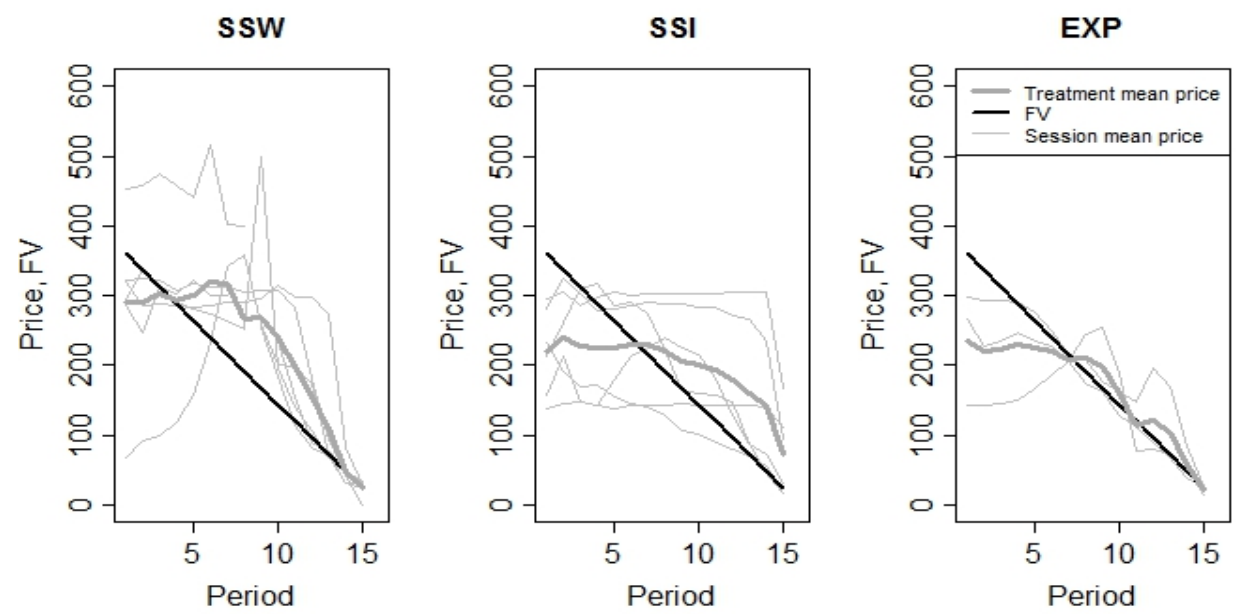

Figure 1 Mean prices by treatments and individual sessions

Table 2 Average bubble measures cross all the sessions in three treatments

\begin{tabular}{|l|c|c|c|c|c|c|c||c|c|c||c|}
\hline ession & $\boldsymbol{P}$ & $\boldsymbol{R A D}$ & $\boldsymbol{R D}$ & $\boldsymbol{A}$ & $\boldsymbol{T D}$ & $\boldsymbol{A B}$ & $\boldsymbol{T O}$ & $\boldsymbol{N D}$ & Boom & Bust & Volatility \\
\hline SWW & 228.44 & 0.408 & 0.178 & 2.14 & 1092 & 41.96 & 5.12 & 11.38 & 8.67 & 3.17 & 15.62 \\
SI & 198.04 & 0.417 & 0.03 & 2.849 & 1189 & 6.15 & $13.78 * *$ & $31.11^{*}$ & 7 & 6.33 & $8.44 * *$ \\
IN-QL6 & - & - & - & 2.17 & $1,443.33$ & -78.5 & 28.17 & 39.13 & 3.7 & 10 & - \\
XXP & 170.08 & 0.236 & -0.107 & 1.01 & 673 & -22 & 7.04 & 9.81 & 4 & 8 & 13.63 \\
\hline
\end{tabular}

Note: 1. P: Mean Price, RAD: Relative Absolute Deviation, $R D$ : Relative Deviation, $A$ : Amplitude, $T D$ : Total Dispersion, $A B$ : Average Bias, TO: Share Turnover, ND: Normalised Deviation, Boom: Number of consecutive periods over FV, Bust: Number of consecutive periods below $F V$, Volatility: Measure for price volatility. 2. The detailed information about each bubble measure refer to Table $1 ; 3 . * * *$ significant at $1 \%, * *$ significant at $5 \%,{ }^{*}$ significant at $10 \% 4$. Bubble measures of all sessions are included in Table A1 in the appendix. 5. HN-QL6 row presents the mean results of same bubble measurements in Haruvy and Noussair (2006) in their QL6 sessions.

For instance, although the average RAD of SSI is higher than those of SSW and EXP, there is no clear indication of over- or under-valuation in SSI indicated by its near-zero $R D$ value and a relatively small $A B$ value. On the other hand, SSW has a similar $R A D$ value as SSI but a higher tendency for overvaluation according to its relatively higher $A B$ value. TO of SSI is significantly higher indicating a higher liquidity in SSI sessions. Furthermore, $N D$ of SSI is also much higher than those of other sessions. Since there is no significant differences for RAD and TD between SSW and SSI, it suggests that the significant difference in their $N D$ is due to the higher trading activity in SSI. In terms of bubble durations, SSW has longer boom durations than those of SSI and conversely for bust duration. 
This is in line with the literature suggesting that short sellers accelerate information releasing by inducing insiders to sell more at higher speed in order to pre-empt the potential competition from short sellers (Massa, et al., 2015).

3.2 Bubble formation and volatility in the presence of an insider

In line with our conjectures, differences emerge when we compare results in our SSI treatment to HNQL6 treatment, in which only short sale is allowed but no insider presents. TD is a measure of how much mean prices deviate from fundamentals, whereas $\mathrm{AB}$ is a measure of variability. If both positive and negative bubbles occur in a session, AB may be low, but TD would still be high. Hence, TD and AB together yield a clearer picture of bubble magnitude and direction (Haruvy and Noussair, 2006). Once an insider is allowed in HN-QL6, TD has reduced but according to AB measure, the large undervaluation observed in HN-QL6 has been alleviated instead there is a small but positive price deviation. Haruvy and Noussair (2006) suggest that short selling may overcompensate for bubbles and lead to undervaluation, which could be translated into a misallocation of capital. The insider trading reduces information asymmetry and enhances liquidity, which allows more informed risk arbitrage hence improves the information efficiency of prices (Bushman et al., 2005; Aussenegg, et al., 2017). The efficacy of short selling depends partly on the proportion of traders using different classes of behavioral strategies. Indeed, in line with the literature (for example, Oechssler, et al., 2011 and Sutter, et al., 2012), SSI results show that by providing some participants with the knowledge of the paid dividend, small positive bubbles can still occur in markets with symmetrically informed 
traders when short selling is allowed. The results are also supported by the Boom and Bust measures.

Once an insider participates, the boom period increases but the bust duration decreases relative to those in HN-QL6. Furthermore, once insider participates in the market where short sale is allowed, there is a noticeable decrease in the turnover. This supports the conjecture based on Sutter, et al (2012) that information asymmetry could make outsiders to trade "more cautiously".

3.3 Bubble formation and volatility in the experience treatment

In EXP sessions we can find the lowest bubble measure values, compared with SSW and SSI treatments. This result holds for all bubble measurements. At the same time, EXP sessions show the lowest boom duration and the highest bust duration among the three treatments. Nevertheless, we find much lower turnover/liquidity in EXP compared with SSI, for example, TO in EXP is half of that in SSI and $N D$ is three times smaller than that of SSI. However, when we compare EXP to HN-QL6, the results show that the size of bubbles (TD) is smaller while the direction of bubble (AB) is still negative. Hence it suggests that the undervaluation phenomenon still exists in EXP but the negative bubble is smaller in EXP than that in the HN-QL6 treatment. It seems that the reduced asymmetry information between outsiders and the insider via experience could work to some extent like a "true" insider but the efficacy in reducing negative bubble is still not as effective. This is also true for turnover, the less information disadvantage via experience does not make overall trading as active as in SSI. Hence such levels of trading by experienced traders are not aggressive enough to arbitrage away all the mispricing in the market. 


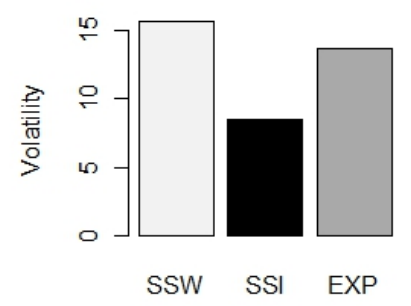

Figure 2 Mean volatility by treatments

In terms of volatility, bubble volatility is statistically significantly lower (half of the size) in SSI compared to SSW (Figure 2), clearly indicating higher market efficiency when both short selling and an insider are allowed in SSI session. Interestingly, we do not find this pattern in EXP. Instead, we find similar levels of liquidity and volatility in EXP as in SSW.

We sum up the comparisons of the treatments in view of bubble formation and volatility in sections 3.1 to 3.3 as the following.

\section{Result 1: Comparisons of Bubble formation and volatility among different treatments}

SSW/SSI: Smaller bubbles are still apparent in sessions where short selling is allowed and an insider with the knowledge of the paid dividends is present in a session. Volatility is significantly lower in SSI, though liquidity is relatively higher in SSI compared to SSW.

SSI/HN-QL6: The large undervaluation due to overcompensation observed in HN-QL6 has been alleviated instead there is a small but positive price deviation in SSI. The outsider trades more cautiously once an insider participates hence the overall turnover reduces in SSI relative to HN-QL6.

SSW/EXP: Bubbles are much smaller in EXP, but the levels of liquidity and volatility are 
approximately the same as those in SSW.

SSI/EXP: Bubbles are more apparent in SSI. At the same time liquidity in SSI is higher than that in EXP. However, volatility in SSI is significantly lower than EXP.

EXP/HN-QL6: The information gained by outsiders via experience can alleviate the undervaluation in HN-QL6 to smaller extent compared to those in SSI. This is also true for turnover, the less information disadvantage via experience does not make overall trading more active than that in SSI.

\subsection{Potential learning effects}

In order to de-puzzle the interesting pattern we find in EXP in section 3.3 and to see if there are any learning effects, in this section, we compare the three treatments based on different phases of a market. It is possible that bubbles occur at different stages of the 15 periods. To examine any potential dynamic patterns in bubble formation in the treatments, we divide each session into three phases, each of which has five periods. Table 3 and Figure 3 present the same bubble measures as in Table 2 and Figure 1 but for each phase cross all the sessions.

3.4.1 Bubble formation and volatility in Phase 1 - Periods 1-5

In terms of bubble sizes, results in Figure 3 and Tables 3 (considering RD and AB) suggest that there is a relatively small tendency of undervaluation in SSW but a much larger undervaluation tendencies in SSI and EXP treatments, though the differences are not statistically significant. Similar to results 
in section 3.1, liquidity (see $T O$ and $N D$ ) is significantly higher in SSI than in other treatments.

Although there is no significant difference in bubble volatility, bubble volatility is the lowest in SSI among the three treatments. Compared with HN-QL6, most of the SSI results of phase 1 are consistent with section 3.2 except that there is even larger undervaluation in SSI (based on AB) than in HN-QL6. On the other hand, the results of EXP in phase 1 are consistent with section 3.3

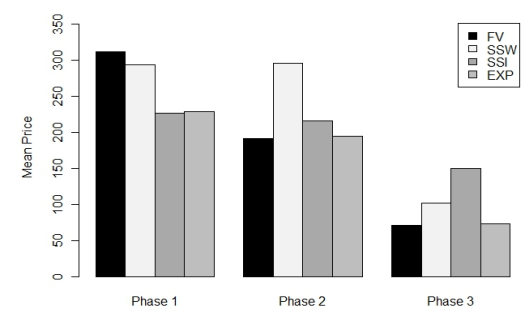

Figure 3: Mean prices in all treatments by phases.

Note: Phase 1: periods 1-5; Phase 2: periods 6-10; Phase 3: periods 11-15

Table 3 Bubble measures for treatments over three phases

\begin{tabular}{|l|c|c|c|c|c|c||c|c||c||c|c|}
\hline ession & P & RAD & RD & A & TD & AB & TO & ND & Boom & Bust & Volatility \\
\hline SW Phase 1 & 294.17 & 0.25 & -0.054 & 0.346 & 384 & -8.75 & 0.35 & 7.29 & 2.5 & 2.5 & 4.67 \\
SI Phase 1 & 226.93 & 0.297 & -0.271 & 0.27 & 458 & -82.45 & $5.48^{* *}$ & $16.42^{*}$ & $0.83^{*}$ & $4.16^{*}$ & 3.04 \\
XP Phase 1 & 228.51 & 0.279 & -0.272 & 0.225 & 436 & -85.03 & 2.74 & 7.26 & 0.66 & 4.32 & 4.16 \\
\hline SW Phase 2 & 295.4 & 0.601 & 0.474 & 1.37 & 511 & 102.27 & 1.15 & 2.59 & 4 & 2.5 & 5.32 \\
SI Phase 2 & $216.41^{*}$ & $0.344 *$ & 0.132 & $0.504 * * *$ & $332 *$ & $25.22^{*}$ & $4.56^{* *}$ & $8.14 *$ & 2.83 & 2 & $2.08^{* * *}$ \\
XX Phase 2 & 194.55 & 0.126 & 0.04 & 0.308 & 121 & 17.64 & 1.8 & 0.91 & 2 & 2.66 & 4.68 \\
\hline SW Phase 3 & 102.34 & 0.575 & 0.488 & 1.19 & 197 & 32.35 & 1.19 & 1.5 & 2.83 & 1.33 & 4.89 \\
SI Phase 3 & 150.46 & 1.134 & 1.077 & 1.99 & 399 & 75.28 & $3.74 * * *$ & 8.55 & 4 & 1.22 & $2.87 * *$ \\
XP Phase 3 & 73.64 & 0.339 & 0.16 & 0.639 & 116 & 9.97 & 2.5 & 1.64 & 3 & 2 & 3.68 \\
\hline Avg.SSI cross & 197.93 & 0.59 & 0.31 & 0.92 & 396.33 & 6.02 & 4.59 & 11.04 & 2.55 & 2.46 & 2.66 \\
\hline phases & & & & & & & & & & \\
\hline Avg. EXP cross & 165.57 & 0.25 & -0.02 & 0.39 & 224.33 & -19.14 & 2.35 & 3.27 & 1.89 & 2.99 & 4.17 \\
\hline phases & & & & & & & & & & \\
\hline IN-QL6 & & & & 2.17 & $1,443.33$ & -78.5 & 28.17 & 39.13 & 3.7 & 10 & \\
\hline
\end{tabular}

Note: 1 . The detailed information about each bubble measure refer to Table $1 ; 2{ }^{* * *}$ significant at $1 \%$, ${ }^{* *}$ significant at $5 \%$, * significant at $10 \% ; 3$. The results show that volatility is lower in all phases in SSI and in all phases bubbles are smaller in EXP. 
3.4.2 Bubble formation and volatility in Phase 2 - Periods $6-10$

Results of phase 2 in Table 3 are the most significant among all three phases. The bubble size in SSI is significantly smaller than that in SSW according to RAD and TD. Amplitude (A) measures the difference between the largest and the smallest deviations from FV. Results show that amplitude of SSI is significantly smaller than that of SSW, indicating smaller variance in prices deviations. The highly significant volatility results are in line with this finding. Furthermore, volatility in SSI in phase 2 is around $32 \%$ lower than that in phase 1 in SSI. The result on liquidity is consistent with phase 1 in the sense that liquidity (see TO and ND) is significantly higher in SSI than other treatments. In terms of bubble duration, SSI has significantly shorter boom duration than that of SSW but significantly longer bust duration that that of SSW. These results are consistent with those in section 3.1. Compared with HN-QL6, all results of phase 2 are consistent with the comparisons made in section 3.2. However, the results of EXP in phase 2 has a noticeable change relative to HN-QL6 in the sense that the undervaluation in HN-QL6 is replaced by a small positive bubble in EXP.

3.4.3 Bubble formation and volatility in Phase 3 - Periods 11-15

In terms of bubble size, most of the measures suggest that phase 3 has large bubbles especially in SSI mostly due to overvaluation, though the results are not statistically significant. Nevertheless, we cannot conclude that bubbles in SSI are larger than those in SSW in phase 3. According to Haruvy and Noussair (2006), mean price tends to stay almost constant for a long period. This pattern does not 
emerge as strongly in sessions where short selling is not allowed. According to the individual session plot of mean price in SSI (Figure A2 in the appendix), the high aggregate value is driven by the results of session SSI1 and SSI4. This result is not surprising since the FV is declining but mean prices stay almost constant. In terms of liquidity and volatility, the results are consistent with the last two phases. Compared with HN-QL6, all the results of phase 3 are consistent with the comparisons made in section 3.2. Consistent with the results of EXP in phase 2, the undervaluation in HN-QL6 is still replaced by a small positive bubble in EXP. It seems that the outsiders do learn and become more experienced in the later phases, during which they become more effective in eliminating negative bubbles and even start creating positive bubbles relative to the first phase.

We sum up the discussions in section 3.4 as the following.

Result 2: Comparisons of Bubble formation and volatility based on segmentation of the sessions in three phases

SSW/SSI: Bubbles are significantly smaller in SSI. Liquidity in SSI in all phases is significantly higher. Volatility is lower in all phases in SSI but significantly different especially in later phases. Hence the interaction with other types of "informed" investors does enhance the propagation of new information by insiders and significantly affect the market efficiency especially at later phases once they have learned.

SSI/HN-QL6: The results of three phases on average are highly consistent with the results of 
different sessions in section 3.2. The large undervaluation observed in HN-QL6 is replaced by a small overvaluation in SSI. The outsiders trade more cautiously once an insider participates hence the overall turnover decreases in SSI relative to HN-QL6.

SSW/EXP: Bubbles are smaller in EXP in all phases. EXP session has higher liquidity than SSW in all phases despite trading activity increases over the three phases gradually in SSW. It seems that the reduced information asymmetry between outsiders and the insider via experience could also work to some extent like a "true" insider and contribute to the improvement of market efficiency. In all phases, volatility in EXP is slightly higher compared to that in SSW.

SSI/EXP: In all phases, bubbles are much smaller in EXP. Consistent with results in section 3.3, EXP has lower liquidity but higher volatility than SSI.

EXP/HN-QL6: It seems that the outsiders do learn and become more experienced in the later phases, during which they become more effective in eliminating negative bubbles and even creating positive bubbles relative to the first phase.

3.5 The Insider's behaviour and her profitability

In this section, we focus on the insider's behaviour and her profitability. Figure 4 shows that the insider only obtains the highest profit in SSI4 among all the participants in the session. In the presence of short sellers, insiders would fear that short sellers have access to the same information and hence compete with them to trade with this information advantage. Consequently, the fear of 
such trading competition could drive down the price at which insiders can sell their shares hence endanger the profitability of insider sales (Foster and Viswanathan, 1993). The profit distribution crosses all the participants vary considerably. For instance, the highest profit is 1.7 times higher than the second highest one (session SSI3) while the highest profit (belongs to the insider) is 2.6 times larger than the second highest profit (SSI4). ${ }^{10}$ However, the insider gains the lowest profit in EXP1 and EXP3. In line with our expectation, experience can contribute to the alleviation of information asymmetry and hence profit inequality between the insider and the outsiders (Haruvy, et al., 2007; Sutter, et al., 2012).

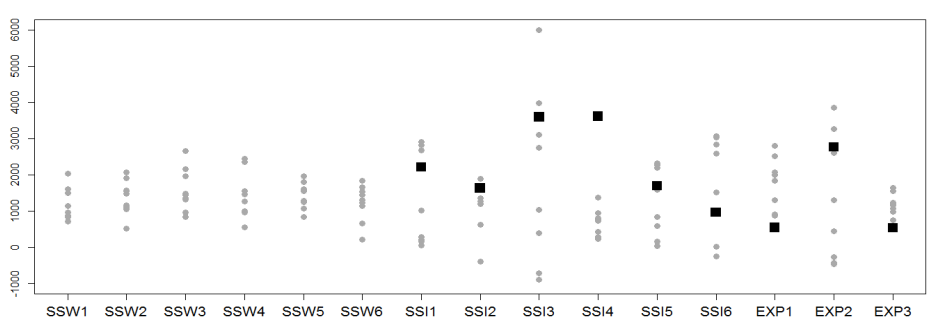

Figure 4 Profits of all participants in all sessions

Note: The figure shows that the profit distributions of all the participants vary considerably. The insider's profit is marked in bold.

Although the insider is not always able to obtain the highest profit, in line with our conjecture, she is the almost always the most active seller as illustrated in Figure 5. The results lend support to the empirical findings in Massa et al. (2015). It shows that the presence of the short seller could induce insiders to sell more and faster to pre-empt the potential competition from short sellers. The finding is important as it shows that the interaction with other types of "informed" investors may enhance the propagation of new information by insiders and significantly affect the financial markets efficiency.

10 Table A2 in the appendix shows the detailed profit distributions of each session. 
For instance, in SSI3 and SSI4, the selling-propositions by the insider are significantly larger than those of the other participants. Particularly in SSI6, the selling-propositions of the insider is as large as those of all the other participants combined. We observe similar results in EXP sessions.
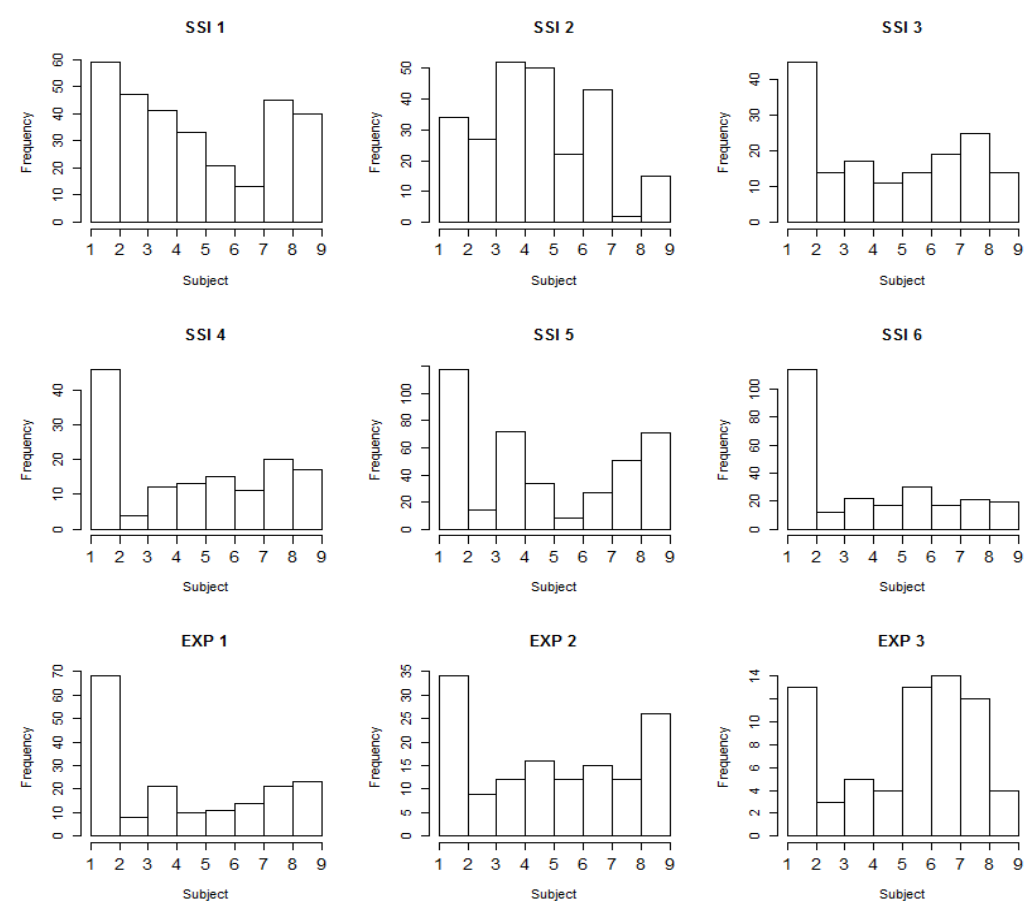

Figure 5 Proposed sales by subjects in each session

Note: The insider is always marked as the first subject in each graph.

To further understand the insider's behavior, Figure 6 presents all selling and buying-propositions (in grey and black respectively) by differentiating the declined propositions (marked as crosses) from the accepted propositions (marked as dots). The intrinsic value is presented as the solid grey line and the average price is indicated by the solid black line. Results in Figure 6 show that the insider's trading decisions are largely based on the average price instead of on the fundamental value in most of the sessions, especially in SSI4 and SSI5. Except for these last periods in SSI4, the insider uses the average price as the reference point since selling prices and selling-propositions are centred on the 
average price instead of on the intrinsic value. In SSI4, she is almost always willing to buy assets a little lower than their average prices but considerably larger than their intrinsic value except for the last periods, where she tries to buy excessively below the intrinsic value. In SSI, the insider sells assets at the price around 100 ECU lower than their current intrinsic value but also buys assets at the prices that are lower than their intrinsic value. This is also observed in SSI 6 where the intrinsic value seems to be irrelevant for the insider's trading decisions. These patterns are still apparent in all the EXP sessions.

Furthermore, we investigate whether and how the profit is distributed unequally between the insider and the rest of the participants. Although the insider did not always obtain the largest profit, we observe obvious inequality in the absolute term. For example, the insider earns 2250 ECU more profit than the second highest profit in SSI4 (Table A2 in the appendix). Such inequality is even more noticeable when we take into account the low dividend distributed in all sessions of this experiment. To measure the inequality of profit distribution more formally, we use the Gini-coefficient and the Lorenz curve $^{11}$. A zero Gini-coefficient value indicates equally distributed profits while the closer it is to one, the more unequally distributed they are. According to the mean Gini-coefficient of each

\footnotetext{
11 The Lorenz curve is a graphical representation of the distribution of income, where it shows for the bottom $\mathrm{x} \%$ of households, what percentage $(\mathrm{y} \%)$ of the total income they have. In the case of perfectly equal income distribution the bottom $\mathrm{N} \%$ of society would always have $\mathrm{N} \%$ of the income. This can be represented by the straight line $y=x$; called the "line of perfect equality." While in the case of a perfectly unequal distribution, the curve would be at $\mathrm{y}=$ $0 \%$ for all $\mathrm{x}<100 \%$, and $\mathrm{y}=100 \%$ when $\mathrm{x}=100 \%$. This curve is called the "line of perfect inequality." The Gini coefficient is the ratio of the area between the line of perfect equality and the observed Lorenz curve to the area between the line of perfect equality and the line of perfect inequality. The higher the coefficient, the more unequal the distribution is.
} 
treatment (Table 4), profits are distributed more equally in SSW since SSW has the lowest mean Gini-coefficient among all the treatments. While when information asymmetry concentrates on a single insider (SSI), the profit distributions turns much more unequal as expected. However, in most of the EXP sessions, once the outsiders build up experience hence reduce their information asymmetry relative to the insider, it helps to alleviate the inequality in profit distributions. Figure 7 plots the Lorenz curve of individual session and they provide a consistent conclusion.

SSI 1

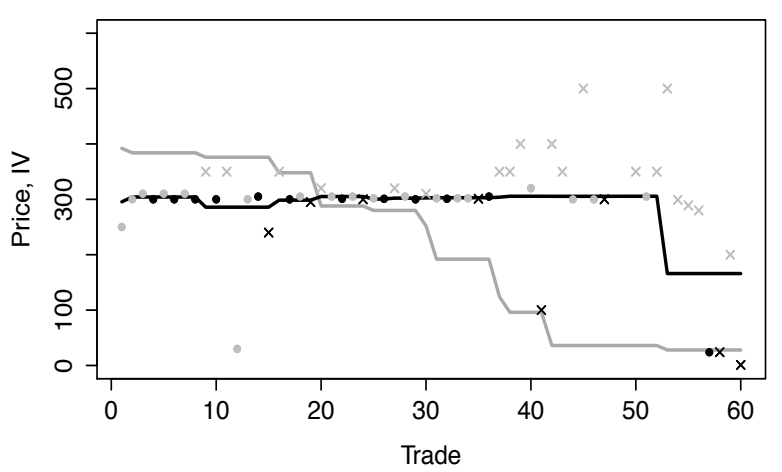

SSI 3

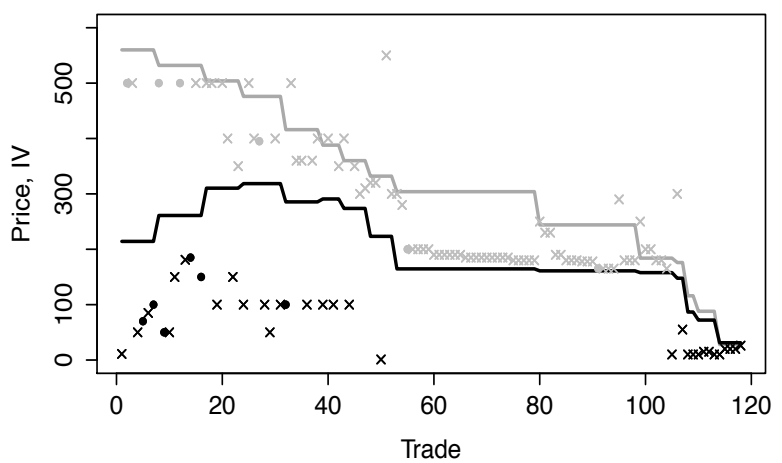

SSI 5

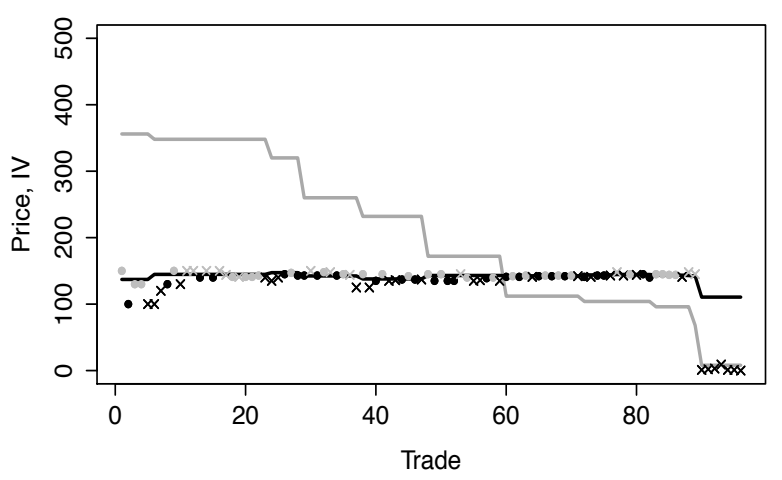

SSI 2

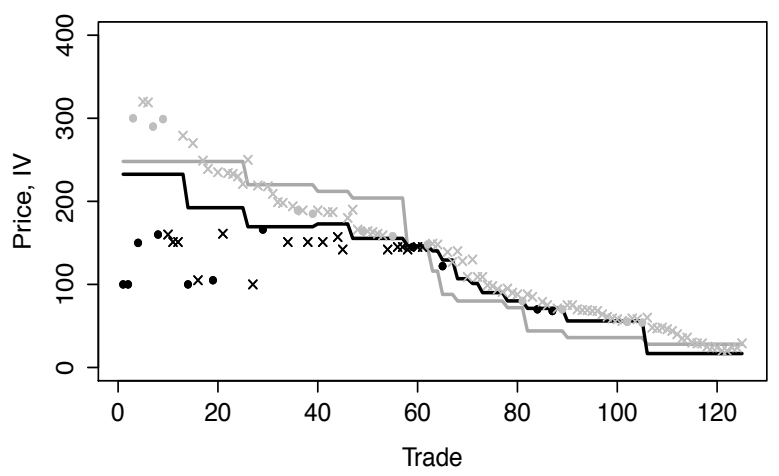

SSI 4

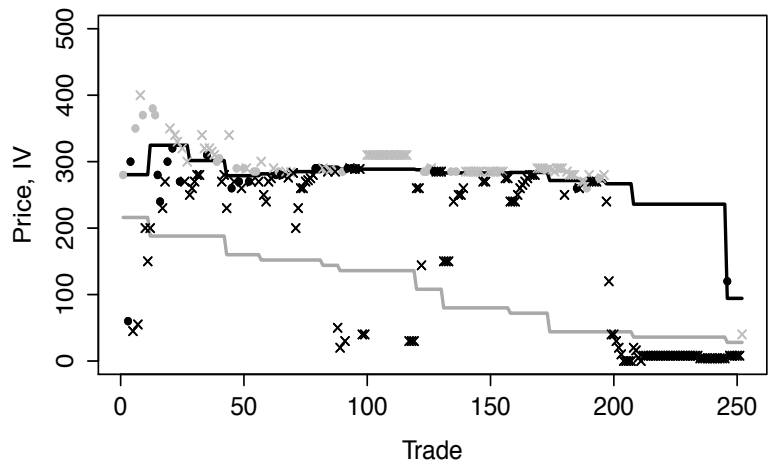

SSI 6

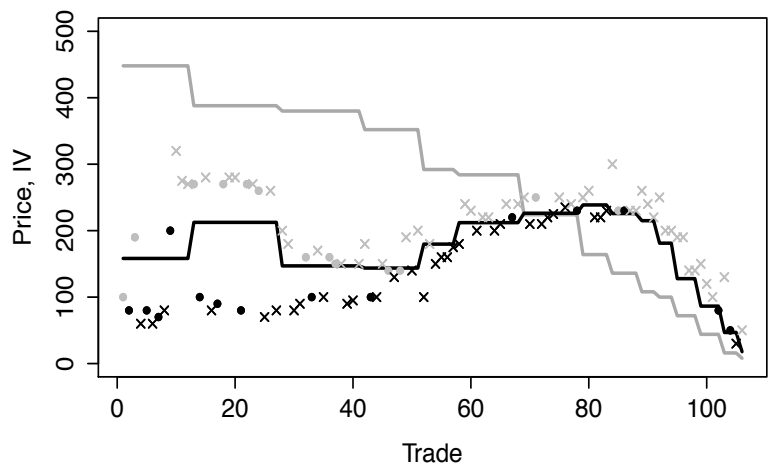


EXP 1

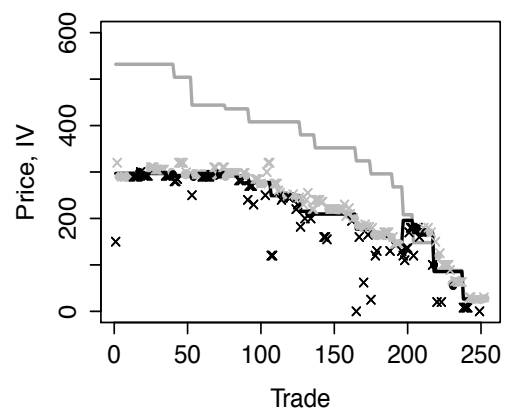

EXP 2

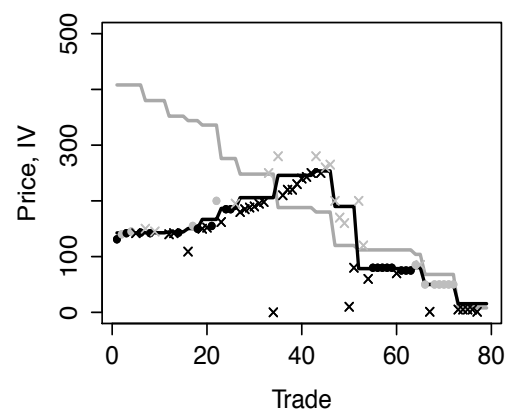

EXP 3

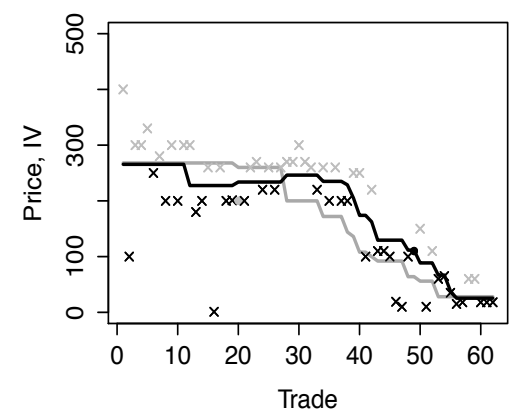

Figure 6 (sales) An insider behavior in SSI-sessions

Note: The intrinsic value is given as the solid grey line, the black line is the average price. Sale-propositions are coloured in grey, buying-propositions are coloured in black. Accepted propositions are marked as dots, rejected propositions are marked as crosses. Results show that the insider uses the average price instead of intrinsic value as the reference point.

Table 4 The mean Gini coefficient of each treatment

\begin{tabular}{|c|c|}
\hline Session & Gini \\
\hline SSW & 0.191 \\
SSI & $0.427^{* * *}$ \\
EXP & 0.347 \\
\hline
\end{tabular}

Note: 1 . The statistical significance is based on the two-sided Wilcoxon signed-rank test. $2 . * * *$ significant at $1 \%$

We sum up the results in section 3.5 as the following.

\section{Result 3: The insider's behaviour and her profitability}

Profitability: The insider does not always earn the largest profit among all the participants in the sessions she takes part in.

Selling: The insider is almost always the most active seller among all the participants. In both SSI and EXP sessions, the insider bases her investment decision mostly on the average price instead of on the intrinsic value.

Profit distribution: When an insider knows the intrinsic value and subjects are able to sell short, profits are more unequally distributed compared to a market where neither any insider nor short 
selling is allowed. However, when other participants reduce their information asymmetry relative to the insider via trading experience, it helps to alleviate the inequality in profit distributions in EXP.
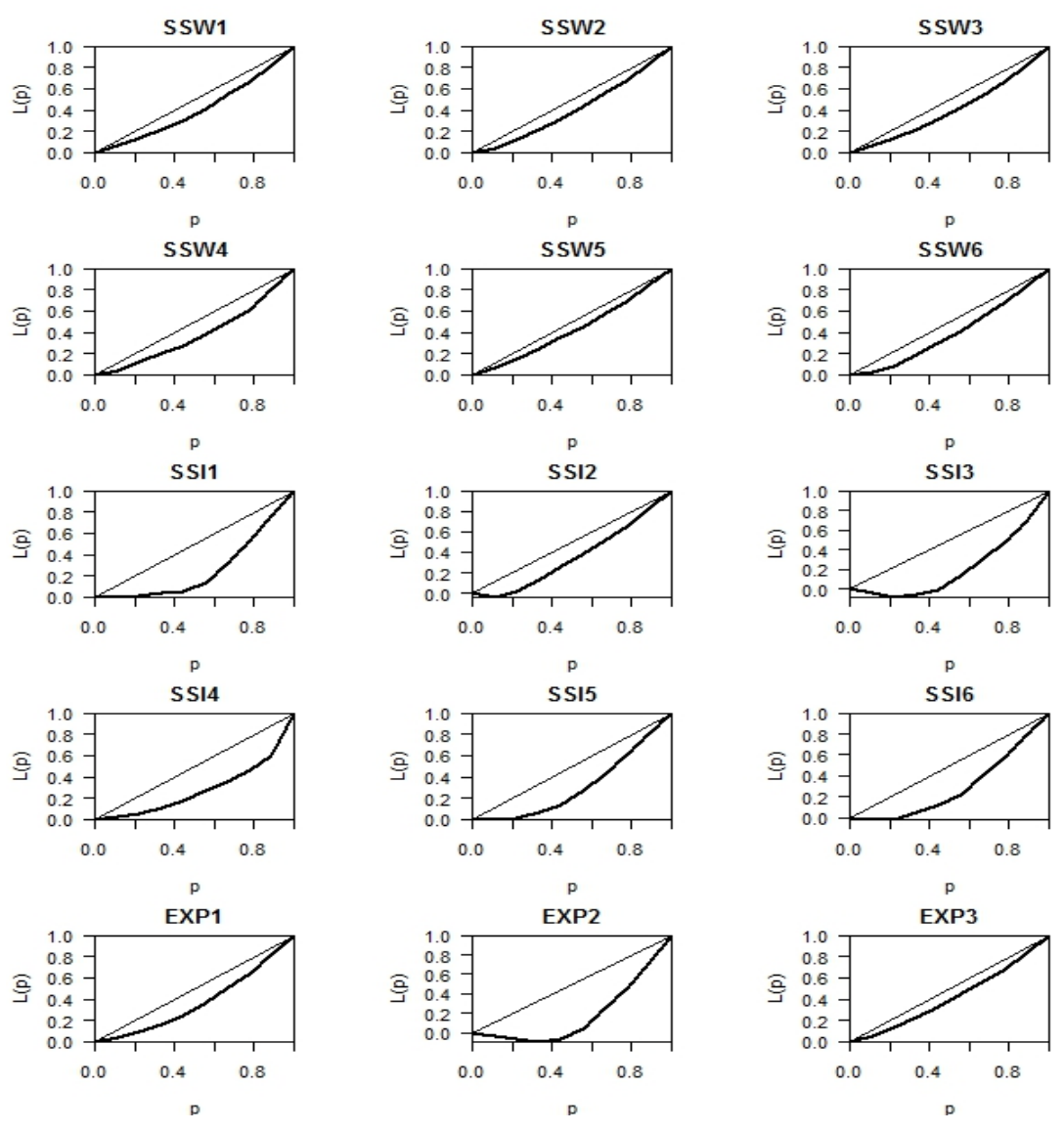

Figure 7 Lorenz curves of profit distributions in all sessions

\section{Conclusion}

Built upon classic SSW (1988) setting, our study extends the institutional design in HN-QL6 to test an explicit economic channel through which short selling can (indirectly) improve the price efficiency of the economy via their influence on insiders. Our experiment designs facilitate subjects' comprehension of the connection between the expected future dividend stream and the current value a rational trader places on the asset by first introducing an insider and then introducing the experienced outsiders. Our results suggest that the presence of the single insider does reduce the large 
undervaluation in pure short selling treatment in HN-QL6 and generates small positive bubbles. Furthermore, once the uninformed outsiders become informed by building up experience in trading, their trading can alleviate the undervaluation in HN-QL6 with even smaller positive bubbles than those sessions without experienced subjects. It suggests that institution design on insider trading restrictions can be offset to some extent by those experienced subjects in terms of bubble formation. In the presence of an insider, the overall turnover is smaller compared to HN-QL6 because outsiders trade even more cautiously facing information asymmetry. Furthermore, the reduced information asymmetry between outsiders and the insider via experience makes volatility significantly smaller. These results provide support to the literature by showing that the interaction with other types of "informed" investors can accelerate the release of new information by insiders and significantly affect the financial market efficiency.

In line with the literature (Plott and Sunder, 1982; Massa, et al., 2015), with the presence of short sellers, the insider is a very active trader and almost always the most active seller. However, the insider does not always gain the highest profit among the subjects even though profits are more unequally distributed in SSI. In the presence of short sellers, insiders fear for potential trading competitions from short sellers, who may have similar information advantage. Therefore, the insider trades faster in order to pre-empt such competition but such fear could also drive down the price at which insiders can sell their shares hence endanger the profitability of insider sales. Contrary to the expectation, the insider's trading decision is mostly influenced by the average prices rather than by 
the intrinsic value due to the nature of the game.

Overall our results show institutional arrangement can have important influences on bubbles. The effectiveness of short selling can be affected by the level of information asymmetry among the traders hence their behavioral strategies. Therefore, financial authorities concern on financial bubbles need to take both short selling and insider efficacies into account for their net impacts. 


\section{References}

Ackert, L.F., Charupat, N., Church, B.K. and Deaves, R., 2006. Margin, short selling, and lotteries in experimental asset markets. Southern Economic Journal, pp.419-436.

Aussenegg, W., Jelic, R. and Ranzi, R., 2017. Corporate insider trading in Europe. Journal of International Financial Markets, Institutions and Money. Forthcoming.

Brislin, R.W., 1970. Back-translation for cross-cultural research. Journal of Cross-cultural Psychology 1, pp.185 - 216.

Bushman, R.M., Piotroski, J.D. and Smith, A.J., 2005. Insider trading restrictions and analysts' incentives to follow firms. The Journal of Finance, 60(1), pp.35-66.

Chiang, C.H., Chung, S.G. and Louis, H., 2017. Insider trading, stock return volatility, and the option market's pricing of the information content of insider trading. Journal of Banking \& Finance, 76, pp.65-73.

Diether, K.B., Lee, K.H. and Werner, I.M., 2009. It's SHO Time! Short - Sale Price Tests and Market Quality. The Journal of Finance, 64(1), pp.37-73.

Dufwenberg, M., Lindqvist, T., Moore, E., 2005. Bubbles and experience: An experiment. American Economic Review 95, pp.1731 - 1737.

Engelberg, J.E., Reed, A.V. and Ringgenberg, M.C., 2012. How are shorts informed?: Short sellers, news, and information processing. Journal of Financial Economics, 105(2), pp.260-278. 
Fellner, G., Theissen, E., 2014. Short sale constraints, divergence of opinion and asset prices: Evidence from the laboratory. J. Econ. Behav. Organ. 101, pp.113-127.

Fischbacher, U., 2007. z-Tree: Zurich toolbox for ready-made economic experiments. Experimental Economics 10, pp.171 - 178.

Foster, F.D. and Viswanathan, S., 1993. The effect of public information and competition on trading volume and price volatility. The Review of Financial Studies, 6(1), pp.23-56.

Füllbrunn, S., Neugebauer, T., 2012. Margin trading bans in experimental asset markets. The Jena Economic Research Papers 2012 - 058.

Gider, J. and Westheide, C., 2016. Relative idiosyncratic volatility and the timing of corporate insider trading. Journal of Corporate Finance, 39, pp.312-334.

Hanke, M., Huber, J., Kirchler, M., Sutter, M. 2010. The economic consequences of a Tobin tax - An experimental analysis. Journal of Economic Behavior and Organization 74, pp.58 - 71.

Haruvy, E., Lahav, Y., Noussair, C.N., 2007. Traders' expectations in asset markets: Experimental evidence. American Economic Review 97, pp.1901-1920.

Haruvy, E., Noussair, C. 2006. The effect of short selling on bubbles and crashes in experimental spot asset markets. Journal of Finance 61, pp.1119 - 1957.

Hirshleifer, D., Teoh, S.H. and Yu, J.J., 2011. Short arbitrage, return asymmetry, and the accrual anomaly. The Review of Financial Studies, 24(7), pp.2429-2461. 
Karpoff, J.M. and Lou, X., 2010. Short sellers and financial misconduct. The Journal of Finance, 65(5), pp.1879-1913.

King, R., Smith, V., Williams, A., 1993. The robustness of bubbles and crashes in experimental stock markets. In: Day, Richard and Ping Chen (eds), Nonlinear Dynamics and Evolutionary Economics, 183-200. Oxford: Oxford University Press.

Lei, V., Noussair, C.N. and Plott, C.R., 2001. Nonspeculative bubbles in experimental asset markets: Lack of common knowledge of rationality vs. actual irrationality. Econometrica, 69(4), pp.831-859.

Massa, M., Qian, W., Xu, W. and Zhang, H., 2015. Competition of the informed: Does the presence of short sellers affect insider selling? Journal of Financial Economics, 118(2), pp.268-288.

Oechssler, J., Schmidt, C., Schnedler, W., 2011. On the ingredients for bubble formation: Informed traders and communication. J. Econom. Dynam. Control 35 (11), pp.1831-1851.

Palan, S., 2013. A review of bubbles and crashes in experimental asset markets. Journal of Economic Surveys 27 (3), pp.570-588.

Plott, C., Sunder, S., 1982. Efficiency of experimental security markets with insider information: An application of rational-expectations models. Journal of Political Economy 90, pp.663 - 698 .

Saffi, P.A. and Sigurdsson, K., 2010. Price efficiency and short selling. The Review of Financial Studies, 24(3), pp.821-852. 
Smith, V., Suchanek, G., Williams, A., 1988. Bubbles and crashes and endogenous expectations in experimental spot asset markets. Econometrica 56, pp.1119-1151.

Stöckl, T., Huber, J., Kirchler, M., 2010. Bubble measures in experimental asset marekts. Experimental Economics 13, pp.284 - 298.

Sutter, M., Huber, J., Kirchler, M., 2012. Bubbles and information: An experiment. Management Science 58, pp.384 - 393.

To, T.Y., Treepongkaruna, S. and Wu, E., 2017. Are all insiders on the inside? Evidence from the initiation of CDS trading and short selling in the financial sector. Journal of International Financial Markets, Institutions and Money. Forthcoming. 


\section{Appendix A}

Table A1 Bubble measures in all sessions

\begin{tabular}{|c|c|c|c|c|c|c|c|c|c|c|c|c|}
\hline Session & P & RAD & RD & A & TD & AB & TO & ND & Boom & Bust & Volatility & Gini \\
\hline SSW1 & 225.9 & 0.255 & 0.166 & 2.159 & 620 & 34.87 & 4.44 & 3.52 & 10 & 3 & 17.96 & 0.187 \\
SSW2 & 282.71 & 0.593 & 0.443 & 2.147 & 1577 & 104.37 & 2.61 & 6.45 & 8 & 1 & 17.03 & 0.181 \\
SSW3 & 249.32 & 0.355 & 0.28 & 2.362 & 1003 & 57.13 & 5.11 & 7.76 & 11 & 2 & 16.04 & 0.191 \\
SSW4 & 162.45 & 0.575 & -0.144 & 1.68 & 1662 & -27.5 & 9.33 & 35.17 & 7 & 5 & 10.84 & 0.238 \\
SSW5 & 188.64 & 0.256 & -0.017 & 1.508 & 436 & 17.43 & 3.39 & 4.68 & 5 & 4 & 17.6 & 0.136 \\
SSW6 & 261.64 & 0.443 & 0.34 & 2.961 & 1255 & 65.43 & 5.83 & 10.73 & 11 & 4 & 14.26 & 0.212 \\
\hline Average: & 228.44 & 0.408 & 0.178 & 2.14 & 1092 & 41.96 & 5.12 & 11.38 & 8.67 & 3.17 & 15.62 & 0.191 \\
\hline SSI1 & 292.3 & 0.608 & 0.491 & 6.095 & 1673 & 97.13 & 16.61 & 51.52 & 12 & 3 & 5.54 & 0.474 \\
SSI2 & 124.06 & 0.359 & -0.331 & 0.624 & 1003 & -65.13 & 13.61 & 29.37 & 1 & 13 & 7.1 & 0.28 \\
SSI3 & 199.89 & 0.198 & 0.039 & 0.943 & 714 & 0.67 & 8.83 & 14.87 & 6 & 3 & 13.89 & 0.579 \\
SSI4 & 270.4 & 0.485 & 0.383 & 4.138 & 1317 & 81.67 & 7.67 & 17.88 & 11 & 4 & 12.9 & 0.435 \\
SSI5 & 140.35 & 0.49 & -0.252 & 4.224 & 1432 & -49.87 & 21.94 & 56.94 & 5 & 9 & 3.75 & 0.372 \\
SSI6 & 161.25 & 0.364 & -0.15 & 1.07 & 995 & -27.57 & 14 & 28.09 & 7 & 6 & 7.49 & 0.42 \\
\hline Average: & 198.04 & 0.417 & 0.03 & 2.849 & 1189 & 6.15 & $13.78^{* *}$ & $33.11^{* *}$ & 7 & 6.33 & $8.44^{* * *}$ & $0.427 * * *$ \\
\hline EXP1 & 206 & 0.16 & 0.068 & 1.537 & 441 & 12.83 & 9.78 & 7.07 & 8 & 3 & 8.26 & 0.254 \\
EXP2 & 141.66 & 0.393 & -0.246 & 1.114 & 1140 & -51 & 7.56 & 19.25 & 3 & 7 & 13 & 0.624 \\
EXP3 & 162.58 & 0.154 & -0.144 & 0.381 & 438 & -29.07 & 3.78 & 3.1 & 1 & 14 & 19.62 & 0.163 \\
\hline Average: & 170.08 & 0.236 & -0.107 & 1.01 & 673 & -22 & 7.04 & 9.81 & 4 & 8 & 13.63 & 0.347 \\
\hline
\end{tabular}

Table A2 Profits of all participants in all sessions

\begin{tabular}{|c|rrrrrrrrrrrrrrrr|}
\hline Subject & SSW1 & SSW2 & SSW3 & SSW4 & SSW5 & SSW6 & SSI1 & SSI2 & \multicolumn{1}{c|}{ SSI3 } & SSI4 & SSI5 & SSI6 & EXP1 & EXP2 & EXP3 \\
\hline 1 & 839 & 2061 & 1323 & 961 & 1960 & 1660 & 2209 & 1631 & 3599 & $\mathbf{3 6 1 5}$ & 1697 & 966 & 545 & 2765 & 533 \\
2 & 961 & 1167 & 1958 & 1461 & 1242 & 1453 & $\mathbf{2 9 1 0}$ & 1261 & 2751 & 943 & 32 & $\mathbf{3 0 7 2}$ & 902 & -439 & 1070 \\
3 & 1506 & 1104 & 1354 & 544 & 843 & 1137 & 43 & 1187 & 395 & 1365 & 838 & 3040 & 1302 & 446 & 753 \\
4 & 1140 & 1906 & 970 & 2347 & 1280 & 1295 & 153 & 615 & 1031 & 283 & 153 & 2843 & 2007 & 1304 & 987 \\
5 & 1492 & 1552 & 2150 & 1006 & 1260 & 1840 & 2673 & 1357 & 3988 & 736 & 2265 & -249 & 876 & -269 & 1223 \\
6 & 710 & 1482 & 1488 & 1267 & 1066 & 212 & 216 & -392 & -899 & 796 & 1589 & 1524 & 2509 & 2606 & 1167 \\
7 & 2033 & 1564 & 845 & 954 & 1603 & 663 & 280 & $\mathbf{1 8 8 6}$ & $\mathbf{5 9 9 5}$ & 224 & 2190 & 2579 & 2061 & 3857 & $\mathbf{1 6 3 9}$ \\
8 & 878 & 509 & 2653 & 1549 & 1545 & 1531 & 1022 & 1697 & 3112 & 769 & 592 & 935 & $\mathbf{2 8 0 1}$ & -474 & 1549 \\
9 & 1610 & 1048 & 1452 & 2448 & 1810 & 1234 & 2815 & 1351 & -715 & 422 & $\mathbf{2 3 1 7}$ & 8 & 1838 & 3269 & 1168 \\
\hline
\end{tabular}



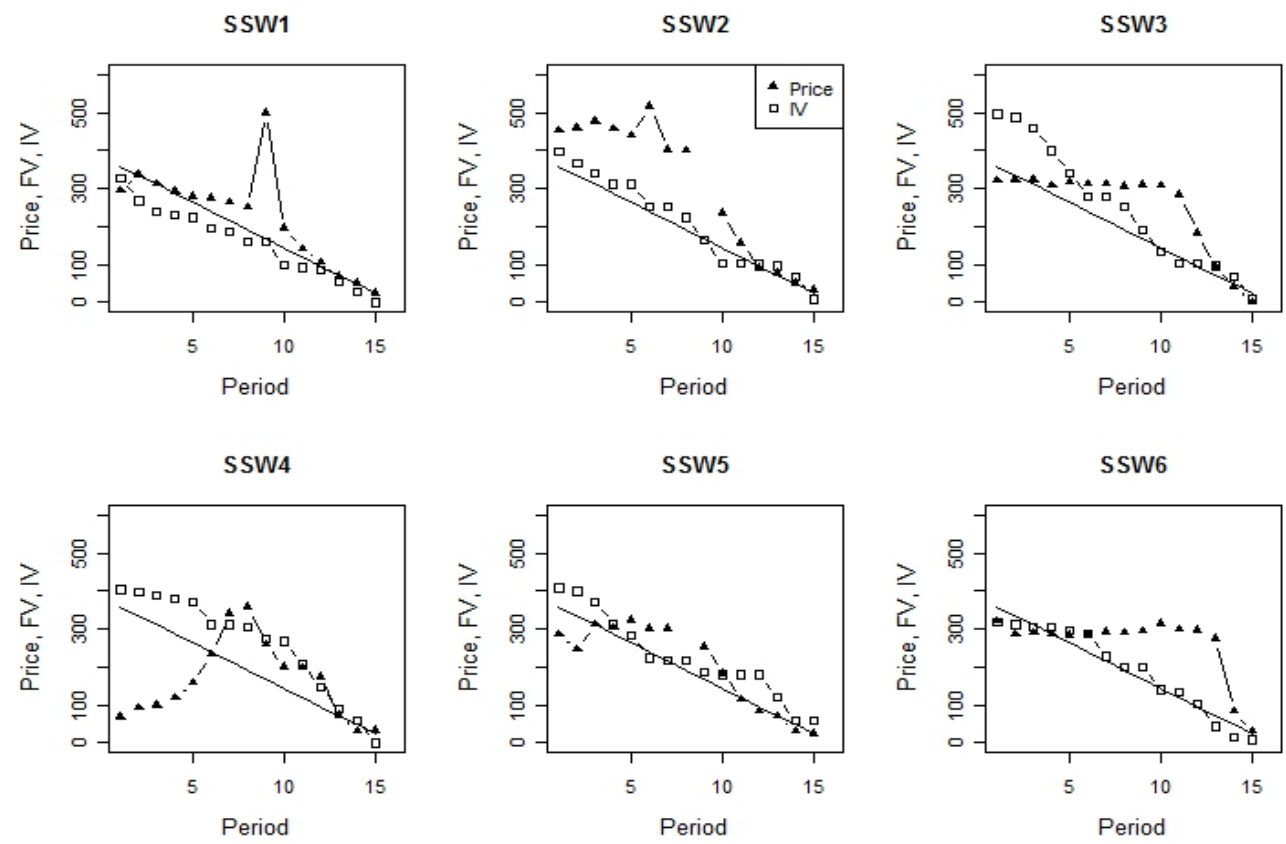

Figure A1: Mean prices in SSW-sessions
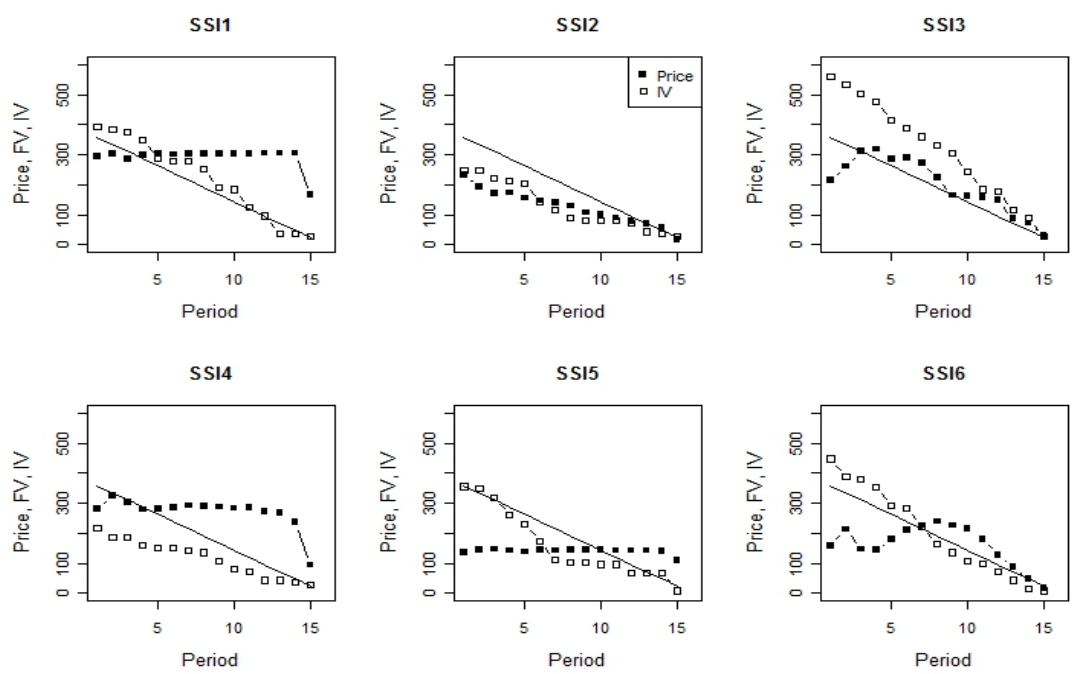

FigureA2: Mean price in SSI-sessions
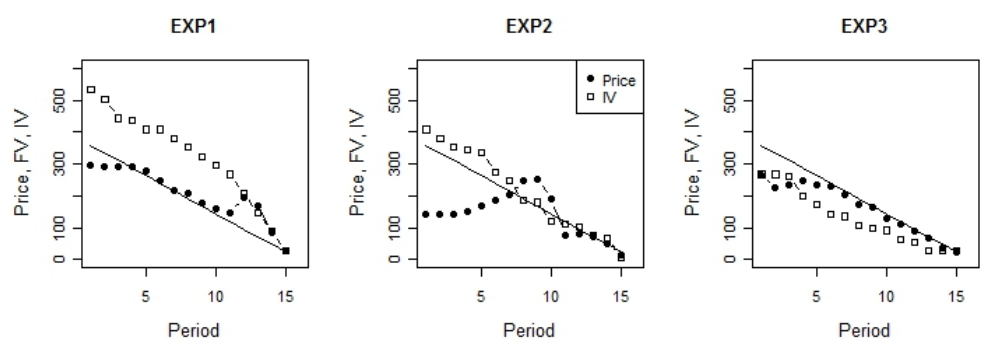

FigureA3: Mean prices in EXP 


\section{Appendix B}

\section{Instructions for experiment (SSI)}

\section{General Instructions}

Welcome!

This is an experiment in the economics of market decision making. The instructions are simple and if you follow them carefully and make good decisions, you might earn a considerable amount of money, which will be paid to you in cash at the end of the experiment.

The experiment will consist of a sequence of trading periods in which you will have the opportunity to buy and sell in a market. Attached to the instructions you will find a sheet, which helps determine the value to you of any decisions you might make. You are not to reveal this information to anyone. It is your own private information.

The currency used in the market is francs. All trading will be in terms of francs. The cash payment to you at the end of the experiment will be in RMB. The conversion rate is 40 francs to 1 yuan. In addition to any profits you earn in the market, you will also receive an additional $¥ 5$ (equivalent to 200 francs) for your participation today.

\section{How to use the computerized market}

The goods that can be bought and sold in the market are called Shares. On the left-most column of your computer screen, in top left corner, you can see the Money you have available to buy Shares and in the middle of the column, you see the number of Shares you currently have.

If you would like to offer to sell a share, use the text area entitled "Enter ask price" in the second column. In that text area you can enter the price at which you are offering to sell a share, and then select "Submit Ask Price". Please do so now.

You will notice that nine numbers, one submitted by each participant, now appear in the third column from the left, entitled "Ask Price". The lowest ask price will always be on the bottom of that list and will be highlighted. If you press "Buy", the button at the bottom of this column, you will buy one share for the lowest current ask price. You can also highlight one of the other prices if you wish to buy at a price other than the lowest.

Please purchase a share now by highlighting a price and selecting "Buy". Since each of you had put a share for sale and attempted to buy a share, if all were successful, you all have the same number of shares you started out with. This is because you bought one share and sold one share.

When you buy a share, your Money decreases by the price of the purchase. When you sell a share your Money increases by the price of the sale.

You may make an offer to purchase a unit by selecting "Submit bid price."

Please do so now. Type a number in the text area "Enter bid price." Then press the red button labeled "Submit Bid Price".

You can sell to the person who submitted an offer if you highlight the offer, and select "Sell". Please do so now for one of the offers.

You will now have a practice period. Your actions in the practice period do not count toward your earnings and do not influence your position later in the experiment. The goal of the practice period is only to master the use of the interface. Please be sure that you have successfully submitted bid prices and ask prices. Also be sure that you have accepted both bid and ask prices. You are free to ask questions, by raising your hand, during the practice period.

\section{Specific Instructions for this experiment}

The experiment will consist of 15 trading periods. In each period, there will be a market open, in which you may buy and sell shares. Shares are assets with a life of 15 periods, and your inventory of shares carries over from one trading period to the next.

Your profits come from two sources - from buying and selling shares and from collecting dividends on all shares you hold at the end of each period. You may receive dividends for each share in your inventory at the end of each of the 15 trading periods.

At the beginning of the experiment, before trading starts, the experimenter will run a computer program to virtually roll a four-sided die 15 times. The 15 numbers are to determine the dividends for 15 trading periods sequentially. Each period, 
each share you hold at the end of the period:

earns you a dividend of 0 francs if the die reads 1

earns you a dividend of 8 francs if the die reads 2

earns you a dividend of 28 francs if the die reads 3

earns you a dividend of 60 francs if the die reads 4

Each of the four numbers on the die is equally likely. The average dividend in each period is 24 . The dividend is added to your cash balance automatically.

After the dividend is paid at the end of period 15, there will be no further earnings possible from shares.

\section{Selling more shares than you own}

It is possible to sell more shares than you own. That is, you may "own" a negative number of shares (up to - 6 shares). In that case, on the negative number of shares you own, you will pay the dividend on each share. For example, suppose you have four shares and you sell ten. You will then have -6 (negative six) shares. Then, as long as you have -6 shares, at the end of each period you must pay dividends on six shares. The computer program will automatically deduct the dividend payment from your earnings.

\section{Your Earnings}

Your earnings for the entire experiment will equal the amount of cash that you have at the end of period 15, after the last dividend has been paid, plus the $¥ 5$ you receive for participating. The amount of cash you will have is equal to:

The cash (called "money" on your screen) you have at the beginning of the experiment

+ dividends you receive (when you have more than zero shares)

- dividends you pay (when you have less than zero shares)

+ money received from sales of shares

- money spent on purchases of shares

\section{Information about Dividends}

There is either an AVERAGE HOLDING VALUE TABLE or an INTRINSIC HOLDING VALUE TABLE attached to your instructions. The AVERAGE HOLDING VALUE TABLE illustrates the average amount of dividend and value of each Share you hold in inventory for each period, while the INTRINSIC HOLDING VALUE TABLE gives the exact amount of dividend and value of each Share you hold in inventory for each period. You can use your table to help you make decisions. Please note that only ONE INTRINSIC HOLDING VALUE TABLE is distributed among all participants.

\section{Contents in AVERAGE HOLDING VALUE TABLE:}

There are 5 columns in the table. The first column, labeled Ending Period, indicates the last trading period of the experiment. The second column, labeled Current Period, indicates the period during which the average holding value is being calculated. The third column gives the number of holding periods from the period in the second column until the end of the experiment. The fourth column, labeled Average Dividend per Period, gives the average amount that the dividend will be in each period for each unit held in your inventory. The fifth column, labeled Average Holding Value Per Unit of Inventory, gives the average value for each unit held in your inventory from now until the end of the experiment. That is, for each unit you hold in your inventory for the remainder of the experiment, you will earn on average the amount listed in column 5 .

Suppose for example that there are 7 periods remaining. Since the dividend on a Share has a $25 \%$ chance of being 0 , a $25 \%$ chance of being 8 , a $25 \%$ chance of being 28 and a $25 \%$ chance of being 60 in any period, the dividend is on average 24 per period for each Share. If you hold a Share for 7 periods, the total dividend for the Share over the 7 periods is on average $7 * 24=168$.

Therefore, the total value of holding a Share over the 7 periods is on average 168 . 


\section{Contents in INTRINSIC HOLDING VALUE TABLE:}

There are 5 columns in the table. The first three columns are exactly the same with those of AVERAGE HOLDING VALUE TABLE. The first column, labeled Ending Period, indicates the last trading period of the experiment. The second column, labeled Current Period, indicates the period during which the average holding value is being calculated. The third column gives the number of holding periods from the period in the second column until the end of the experiment. The fourth column, labeled Dividend per Period, gives the amount that the dividend will be in each period for each unit held in your inventory. The fifth column, labeled Intrinsic Holding Value Per Unit of Inventory, gives the precise value for each unit held in your inventory from now until the end of the experiment. That is, for each unit you hold in your inventory for the remainder of the experiment, you will earn the amount listed in column 5.

Suppose for example that there are 4 periods remaining. The dividends pay off for the last 4 periods are: $8,0,28$ and 60 for each Share. If you hold a Share for 4 periods, the total dividend for the Share over the 4 periods is $8+0+28+60=96$.

Therefore, the total value of holding a Share over the 4 periods is 96 .

Table B1 AVERAGE HOLDING VALUE TABLE

\begin{tabular}{|cccccc|}
\hline $\begin{array}{c}\text { Ending } \\
\text { Period }\end{array}$ & $\begin{array}{c}\text { Current } \\
\text { Period }\end{array}$ & $\begin{array}{c}\text { Number of Holding } \\
\text { Periods }\end{array}$ & $\begin{array}{c}\text { Average Dividend } \\
\text { Per Period }\end{array}$ & $=\begin{array}{c}\text { Average Holding Value } \\
\text { Per Share in Inventory }\end{array}$ \\
\hline 15 & 1 & 15 & 24 & 360 \\
15 & 2 & 14 & 24 & 336 \\
15 & 3 & 13 & 24 & 312 \\
15 & 4 & 12 & 24 & 288 \\
15 & 5 & 11 & 24 & 264 \\
15 & 6 & 10 & 24 & 240 \\
15 & 7 & 9 & 24 & 216 \\
15 & 8 & 8 & 24 & 192 \\
15 & 9 & 7 & 24 & 168 \\
15 & 10 & 6 & 24 & 144 \\
15 & 11 & 5 & 24 & 120 \\
15 & 12 & 4 & 24 & 96 \\
15 & 13 & 3 & 24 & 72 \\
15 & 14 & 2 & 24 & 48 \\
15 & 15 & 1 & 24 & 24 \\
\hline
\end{tabular}

Table B2 INTRINSIC HOLDING VALUE TABLE

\begin{tabular}{|cccccc|}
\hline $\begin{array}{c}\text { Ending } \\
\text { Period }\end{array}$ & $\begin{array}{c}\text { Current } \\
\text { Period }\end{array}$ & $\begin{array}{c}\text { Number of } \\
\text { Holding Periods }\end{array}$ & $\begin{array}{c}\text { Die } \\
\text { Reading }\end{array}$ & $\begin{array}{c}\text { Dividend Per } \\
\text { Period }\end{array}$ & $\begin{array}{c}\text { Intrinsic Holding Value } \\
\text { Per Share in Inventory }\end{array}$ \\
\hline 15 & 1 & 15 & 2 & 28 & 416 \\
15 & 2 & 14 & 2 & 28 & 388 \\
15 & 3 & 13 & 3 & 28 & 360 \\
15 & 4 & 12 & 2 & 8 & 332 \\
15 & 5 & 11 & 1 & 8 & 324 \\
15 & 6 & 10 & 2 & 28 & 316 \\
15 & 7 & 9 & 3 & 60 & 288 \\
15 & 8 & 8 & 2 & 28 & 228 \\
15 & 9 & 7 & 1 & 8 & 200 \\
15 & 10 & 6 & 1 & 8 & 192 \\
15 & 11 & 5 & 2 & 28 & 184 \\
15 & 12 & 4 & 4 & 60 & 156 \\
15 & 13 & 3 & 3 & 28 & 96 \\
15 & 14 & 2 & 2 & 8 & 68 \\
15 & 15 & 1 & 4 & 60 & 60 \\
\hline
\end{tabular}




\section{Appendix C}

\section{Instructions for experiment (EXP)}

\section{General Instructions}

Welcome!

This is an experiment in the economics of market decision making. The instructions are simple and if you follow them carefully and make good decisions, you might earn a considerable amount of money, which will be paid to you in cash at the end of the experiment.

The experiment will consist of a sequence of trading periods in which you will have the opportunity to buy and sell in a market. Attached to the instructions you will find a sheet, which helps determine the value to you of any decisions you might make. You are not to reveal this information to anyone. It is your own private information.

The currency used in the market is francs. All trading will be in terms of francs. The cash payment to you at the end of the experiment will be in RMB. The conversion rate is 70 francs to 1 yuan. In addition to any profits you earn in the market, you will also receive an additional $¥ 5$ (equivalent to 200 francs) for your participation today.

\section{How to use the computerized market}

The goods that can be bought and sold in the market are called Shares. On the left-most column of your computer screen, in top left corner, you can see the Money you have available to buy Shares and in the middle of the column, you see the number of Shares you currently have.

If you would like to offer to sell a share, use the text area entitled "Enter ask price" in the second column. In that text area you can enter the price at which you are offering to sell a share, and then select "Submit Ask Price". Please do so now.

You will notice that nine numbers, one submitted by each participant, now appear in the third column from the left, entitled "Ask Price". The lowest ask price will always be on the bottom of that list and will be highlighted. If you press "Buy", the button at the bottom of this column, you will buy one share for the lowest current ask price. You can also highlight one of the other prices if you wish to buy at a price other than the lowest.

Please purchase a share now by highlighting a price and selecting "Buy". Since each of you had put a share for sale and attempted to buy a share, if all were successful, you all have the same number of shares you started out with. This is because you bought one share and sold one share.

When you buy a share, your Money decreases by the price of the purchase. When you sell a share your Money increases by the price of the sale.

You may make an offer to purchase a unit by selecting "Submit bid price."

Please do so now. Type a number in the text area "Enter bid price." Then press the red button labeled "Submit Bid Price".

You can sell to the person who submitted an offer if you highlight the offer, and select "Sell". Please do so now for one of the offers.

You will now have a practice period. Your actions in the practice period do not count toward your earnings and do not influence your position later in the experiment. The goal of the practice period is only to master the use of the interface. Please be sure that you have successfully submitted bid prices and ask prices. Also be sure that you have accepted both bid and ask prices. You are free to ask questions, by raising your hand, during the practice period.

\section{Specific Instructions for this experiment}

The experiment will consist of two parts - Part 1 and Part 2. In each part, there will be 15 trading periods. In each period, there will be a market open, in which you may buy and sell shares. Shares are assets with a life of 15 periods, and your inventory of shares carries over from one trading period to the next.

Your profits come from two sources-from buying and selling shares and from collecting dividends on all shares you hold at the end of each period. You may receive dividends for each share in your inventory at the end of each of the 15 trading periods.

At the beginning of the experiment, before trading starts, the experimenter will run a computer program to virtually roll a four-sided die 15 times. The 15 numbers are to determine the dividends for 15 trading periods sequentially. Each period, each share you hold at the end of the period:

earns you a dividend of 0 francs if the die reads 1

earns you a dividend of 8 francs if the die reads 2

earns you a dividend of 28 francs if the die reads 3

earns you a dividend of 60 francs if the die reads 4

Each of the four numbers on the die is equally likely. The average dividend in each period is 24 . The dividend is added to 
your cash balance automatically.

After the dividend is paid at the end of period 15, there will be no further earnings possible from shares.

Following the end of Period 15 of Part 1, you will get a screen informing you of the end of Part 1. Part 2 will begin from period 1 with a new 15-period-lived asset.

None of your Shares or Money from Part 1 will transfer to Part 2. Trading and dividends for Part 2 will be the same as in Part 1. At the end of the experiment, your earnings will consist of your earnings for Part 1 plus your earnings for Part 2.

\section{Selling more shares than you own}

It is possible to sell more shares than you own. That is, you may "own" a negative number of shares (up to - 6 shares). In that case, on the negative number of shares you own, you will pay the dividend on each share. For example, suppose you have four shares and you sell ten. You will then have -6 (negative six) shares. Then, as long as you have -6 shares, at the end of each period you must pay dividends on six shares. The computer program will automatically deduct the dividend payment from your earnings.

\section{Your Earnings}

Your earnings for the experiment will consist of the sum of your earnings for part 1 and part 2 . Your earnings for the each of the two parts of the experiment will equal the amount of cash that you have at the end of period 15, after the last dividend has been paid, plus the $¥ 5$ you receive for participating. The amount of cash you will have is equal to:

The cash (called "money" on your screen) you have at the beginning of the experiment

+ dividends you receive (when you have more than zero shares)

- dividends you pay (when you have less than zero shares)

+ money received from sales of shares

- money spent on purchases of shares

\section{Information about Dividends}

There is either an AVERAGE HOLDING VALUE TABLE or an INTRINSIC HOLDING VALUE TABLE attached to your instructions. The AVERAGE HOLDING VALUE TABLE illustrates the average amount of dividend and value of each Share you hold in inventory for each period, while the INTRINSIC HOLDING VALUE TABLE gives the exact amount of dividend and value of each Share you hold in inventory for each period. You can use your table to help you make decisions. Please note that only ONE INTRINSIC HOLDING VALUE TABLE is distributed among all participants.

\section{Contents in AVERAGE HOLDING VALUE TABLE:}

There are 5 columns in the table. The first column, labeled Ending Period, indicates the last trading period of the experiment. The second column, labeled Current Period, indicates the period during which the average holding value is being calculated. The third column gives the number of holding periods from the period in the second column until the end of the experiment. The fourth column, labeled Average Dividend per Period, gives the average amount that the dividend will be in each period for each unit held in your inventory. The fifth column, labeled Average Holding Value Per Unit of Inventory, gives the average value for each unit held in your inventory from now until the end of the experiment. That is, for each unit you hold in your inventory for the remainder of the experiment, you will earn on average the amount listed in column 5 .

Suppose for example that there are 7 periods remaining. Since the dividend on a Share has a $25 \%$ chance of being 0 , a $25 \%$ chance of being 8 , a $25 \%$ chance of being 28 and a $25 \%$ chance of being 60 in any period, the dividend is on average 24 per period for each Share. If you hold a Share for 7 periods, the total dividend for the Share over the 7 periods is on average $7 * 24=168$.

Therefore, the total value of holding a Share over the 7 periods is on average 168 .

\section{Contents in INTRINSIC HOLDING VALUE TABLE:}

There are 5 columns in the table. The first three columns are exactly the same with those of AVERAGE HOLDING VALUE TABLE. The first column, labeled Ending Period, indicates the last trading period of the experiment. The second column, labeled Current Period, indicates the period during which the average holding value is being calculated. The third column gives the number of holding periods from the period in the second column until the end of the experiment. The fourth column, labeled Dividend per Period, gives the amount that the dividend will be in each period for each unit held in your inventory. The fifth column, labeled Intrinsic Holding Value Per Unit of Inventory, gives the precise value for each unit held in your inventory from now until the end of the experiment. That is, for each unit you hold in your inventory for the remainder of the experiment, you will earn the amount listed in column 5.

Suppose for example that there are 4 periods remaining. The dividends pay off for the last 4 periods are: $8,0,28$ and 60 
for each Share. If you hold a Share for 4 periods, the total dividend for the Share over the 4 periods is $8+0+28+60=96$. Therefore, the total value of holding a Share over the 4 periods is 96 .

Table C2 INTRINSIC HOLDING VALUE TABLE (Sample)

\begin{tabular}{|cccccc|}
\hline $\begin{array}{c}\text { Ending } \\
\text { Period }\end{array}$ & $\begin{array}{c}\text { Current } \\
\text { Period }\end{array}$ & $\begin{array}{c}\text { Number of } \\
\text { Holding Periods }\end{array}$ & $\begin{array}{c}\text { Die } \\
\text { Reading }\end{array}$ & $\begin{array}{c}\text { Dividend Per } \\
\text { Period }\end{array}$ & $\begin{array}{c}\text { Intrinsic Holding Value Per } \\
\text { Share in Inventory }\end{array}$ \\
\hline 15 & 1 & 15 & 2 & 28 & 416 \\
15 & 2 & 14 & 2 & 28 & 388 \\
15 & 3 & 13 & 3 & 28 & 360 \\
15 & 4 & 12 & 2 & 8 & 332 \\
15 & 5 & 11 & 1 & 8 & 324 \\
15 & 6 & 10 & 2 & 28 & 316 \\
15 & 7 & 9 & 3 & 60 & 288 \\
15 & 8 & 8 & 2 & 28 & 228 \\
15 & 9 & 7 & 1 & 8 & 192 \\
15 & 10 & 6 & 1 & 8 & 184 \\
15 & 11 & 5 & 2 & 28 & 96 \\
15 & 12 & 4 & 4 & 60 & 68 \\
15 & 13 & 3 & 3 & 28 & 60 \\
15 & 14 & 2 & 2 & 8 & \\
15 & 15 & 1 & 4 & 60 & \\
\hline
\end{tabular}

